\title{
Promosi Kesehatan pada Ibu dan Balita Dalam Rangka Menurunkan Angka Kematian dan Kesakitan Balita "Balita Sehat, Ibu Senang"
}

\author{
Ziyadatul Chusna \\ Email: ayya_chusna@ymail.com \\ Prodi Administrasi Kesehatan, Sekolah Tinggi Ilmu Kesehatan Brebes, Indonesia \\ Jalan Raya Jatibarang Km8 Janegara Jatibarang Brebes \\ Telp/fax. (0283) 6712288
}

\begin{abstract}
Abstrak
Anak sehat cerdas tentunya tidak terlepas dari peran serta orang tua di dalam memberikan asupan gizi nutrisi yang baik dan cukup serta menyehatkan, baik hal ini dilakukan di dalam masa kehamilan sang ibunya maupun ketika sang anak sedang dalam masa keemasan di fase pertumbuhan perkembangan yang menunjang akan kecerdasan otaknya sang anak itu sendiri. Rendahnya kebersihan, tingginya angka kejadian diare dan ketersediaan jamban di desa kendawa menjadi latar belakang kami untuk memberikan materi Promosi Kesehatan Pada Ibu dan balita Dalam Rangka Menurunkan Angka Kematian Bayi di Desa Kendawa Kecamatan Jatibarang Kabupaten Brebes. Metode dalam pelaksanaan Ibu dilakukan dengan metode ceramah, dan diskusi dengan menggunakan leaflet adapun luaran yang diperoleh yaitu meningkatnya kesadaran dan pengetahuan orang tua tentang balita sehat di Desa Kendawa. Luaran yang diperoleh yaitu adanya media pendidikan kesehatan tentangbalita sehat di Desa Kendawa.
\end{abstract}

Kata kunci: pendidikan kesehatan; balita sehat.

\begin{abstract}
Healthy and intelligent children certainly cannot be separated from the role of parents in providing good and sufficient and healthy nutritional intake, whether this is done during the mother's pregnancy or when the child is in a golden age in the growth phase of development that supports intelligence. the child's own brain. The low level of hygiene, the high incidence of diarrhea and the availability of latrines in the village of Kendawa became our background for providing health promotion materials for mothers and toddlers in order to reduce infant mortality in Kendawa Village, Jatibarang District, Brebes Regency. The method in the implementation of the mother is carried out by the lecture method, and discussions using leaflets while the output obtained is increased awareness and knowledge of parents about healthy toddlers in Kendawa Village. The output obtained is the existence of health education media about healthy toddlers in Kendawa Village.
\end{abstract}

Keywords: health education; healthy toddler. 


\section{Pendahuluan}

Kesehatan Balita adalah hal yang paling krusial di dalam tumbuh kembangnya. Pada umumnya, Balita mempelajari lingkungan sekitar dengan menyentuh, mencium dan merasakannya. Umumnya mereka tidak menyadari bahaya yang mungkin terjadi saat mereka sibuk mengeksplorasi lingkungannya. Hal-hal sperti ini dapat mengganggu kesehatan balita di tingkat yang cukup tinggi, jadi tidaklah mengejutkan jika setiap tahun, rumah sakit merawat ribuan anak yang terkontaminasi oleh zatzat berbahaya. ${ }^{(1)}$

Pengetahuan merupakan faktor yang sangat penting dalam membentuk tindakan seseorang sehingga kurangnya pengetahuan tentang kehamilan dapat mempengaruhi seseorang untuk mempunyai perhatian terhadap kesehatan ibu dan bayi. ${ }^{(2)}$

Mengenali akan tanda anak yang sehat dan pandai bagi orang tua adalah merupakan hal yang harus diperhatikan dan tidak boleh untuk diremehkan, karena memang dengan mengetahui akan ciri-ciri anak sehat akan bisa membuat perkembangan dan pertumbuhan sang anak itu sendiri akan lebih baik dan orang tua bisa mengarahkannya ke hal-hal yang bermanfaat baik dalam hal yang berpengaruh terhadap kesuksesan di dunia pendidikannya kelak ketika dewasa dan juga bisa menjadi tahap awal meraih kesuksesan sang anak dalam dunia pekerjaan nantinya. ${ }^{(3)}$

Ciri anak tumbuh sehat akan bisa terlihat dari penampilan fisik maupun mentalitas sang anak, tentunya ini diukur dalam takaran anak, berbeda dengan cara pengukuran dan penilaian terhadap orang dewasa pada umumnya.
Karena dengan kita para orang tua mengetahui apa saja tanda ciri anak cerdas maka kita akan bisa juga menggunakannya hal ini dalam rangka mengenali dan menggali potensi anak kita sendiri. ${ }^{(4)}$

Anak sehat cerdas tentunya tidak terlepas dari peran serta orang tua di dalam memberikan asupan gizi nutrisi yang baik dan cukup serta menyehatkan, baik hal ini dilakukan di dalam masa kehamilan sang ibunya maupun ketika sang anak sedang dalam masa keemasan di fase pertumbuhan perkembangan yang menunjang akan kecerdasan otaknya sang anak itu sendiri. ${ }^{(5)}$

Rendahnya kebersihan, tingginya angka kejadian diare dan ketersediaan jamban di desa kendawa menjadi latar belakang kami untuk memberikan materi Promosi Kesehatan Pada Ibu dan balita Dalam Rangka Menurunkan Angka Kematian Bayi Di Desa Kendawa Kecamatan Jatibarang Kabupaten Brebes dengan Judul Balita Sehat Ibu Senang.

\section{Metode}

Pelaksanaan pengabdian pada masyarakat dilakukan dengan metode ceramah dan diskusi menggunakan media leafleat. Alasan pemilihan media ini adalah karena kelebihannya yaitu: mudah disimpan, ekonomis dan bisa berfungsi sebagai remainder bagi sasaran dan dapat dibawa kemanamana, biaya murah, sehinga media ini cocok untuk penyuluhan. Selain itu leaflet juga dapat digunakan untuk membuka fokus topik yang akan dibahas jika diberikan sebelum penyuluhan dimulai. ${ }^{(6)}$

Tahapan dalam kegiatan ini adalah persiapan dalam bentuk survey pada kelompok sasaran, koordinasi dan pengurusan ijin dengan instansi terkait (desa), 
persiapan media konseling dan sarana prasarana, tahapan selanjutnya yaitu pelaksanaan kegiatan pemberian pendidikan kesehatan tentang Balita Sehat dengan metode diskusi dan Tanya jawab dengan menggunakan media leaflet tahapan terakhir yaitu melakukan follow up kegiatan tersebut.

\section{Hasil dan Pembahasan}

Kegiatan pengabdian ini telah dilaksanakan di Desa Kendawa Kecamatan Jatibrang Kabupaten Brebes yang bertempat di Rumah Kader Ibu Kurniasih pada hari minggu tanggal 8 November 2020 dengan jumlah perserta 15 orang. Peserta adalah orang tua yang memiliki balita, dan kader. Mereka sangat antusias mengikuti kegiatan pendidikan kesehatan tentang Balita Sehat.

Kegiatan pengabdian diawali dengan koordinasi dengan Bidan desa Kendawa untuk mengundang orang tua yang memiliki balita dan kader pada tanggal 8 November 2020 pada saat pelaksanaan diawali dengan pendaftaran peserta yang hadir serta peserta diberikan pertanyaan seputar Balita sehat.

Sebelum dilakukan pendidikan kesehatan tentang gizi seimbang pada balita orang tua diberikan beberapa pertanyaan dengan jumlah 5 pertanyaan tentang Balita sehat, 4 orang menjawab dengan tepat.

Pemberian pendidikan kesehatan tentang Balita Sehat pada orang tua dilaksanakan selama 60 menit dengan metode diskusi dan tanya jawab dimana orang tua dan kader sangat antusias mendengarkan dan mengajukan pertanyaan, diantaranya: ciri balita sehat, tanda bahaya pada balita dan tips menjaga kesehatan balita.
Setelah dilakukan pendidikan kesehatan tentang gizi seimbang pada balita orang tua diberikan beberapa pertanyaan dengan jumlah 5 pertanyaan tentang Balita sehat, 10 orang menjawab dengan tepat.Terjadi peningkatan jumlah penjawab yang menjawab dengan tepat.

\section{Kesimpulan}

Berdasarkan hasil pelaksanaan Pengabdian masyarakat yang telah dilakukan di Desa Kendawa yang dihadiri sebanyak 10 orang tua yang memiliki balita, dan 5 orang kader. Terdapat peningkatan pengetahuan yang signifikan setelah diberikan pendidikan kesehatan dengan media leaflet.

Hasil ini menunjukkan, bahwa intervensi pendidikan kesehatan yang dilakukan dengan singkat akan berdampak positif dalam meningkatkan pengetahuan seseorang ${ }^{(7)}$. Menurut Notoatmojo ${ }^{(8)}$ kegiatan pendidikan kesehatan adalah suatu kegiatan pemberian informasi atau pesan berupa penyuluhan dari pemberi pesan kepada penerima pesan yang tersampaikan, akan membuat peningkatan pengetahuan dan merubah sikap seseorang tentang kesehatan dengan tujuan merubah perilaku manusia secara individu, kelompok ataupun masyarakat agar lebih baik lagi dalam menciptakan perilaku sehat.

Pelaksanaan kegiatan Promosi Kesehatan pada Ibu balita dan Kader, ibu balita dan kader dapat melakukan langkah pemantauan, pencegahan terjadinya kesakitan dan kematian pada balita 


\section{Daftar Pustaka}

[1] E. F. Paath, Gizi Dalam Kesehatan Reproduksi. Jakarta: EGC, 2005.

[2] M. E. Beck, Ilmu Gizi dan Diet (Nutrition and Dietetics for nurses). Yogyakarta: Yayasan Essentia Medica, 2000.

[3] T. Soenardi, Makanan Untuk Tumbuh Kembang Bayi. Jakarta: PT Gramedia Pustaka Utama, 2006.

[4] Soetjiningsih, Seri Gizi Klinis ASI. Jakarta: EGC, 2011.
[5] A. A. Hidayat, Siapa Bilang Anak Sehat Pasti Cerdas 6 kunci sukses mempersiapkan anak tumbuh sehat dan cerdas. Jakarta: PT Elex Media Komputindo, 2007.

[6] D. P. \& PL, Panduan Penggunaan Media Penyuluhan. Jakarta: Departemen Kesehatan RI, 2003. 